\title{
Uso de Cinzas de Biomassa Geradas na Agroindústria do Malte para Produção de Argamassas
}

\author{
Sauana Haeffner Centenaro'; 'João Adriano Godoy da Silva'; Rafaella Salvador Paulinol \\ \rafaellaspaulino@gmail.com
}

1. Faculdade Guarapuava, Vale do Jordão, Guarapuava - PR.

\begin{abstract}
Histórico do Artigo: 0 autor detém os direitos autorais deste artigo.
Recebido em: 16 de setembro de 2020 Aceito em: 13 de janeiro de $2021 \quad$ Publicado em: 31 de agosto de 2021
\end{abstract}

\begin{abstract}
Resumo: Nas maltarias, madeira de eucalipto e resíduos da agroindústria, como grãos e cascas, são utilizadas como combustível de caldeiras, gerando cinzas, cujas propriedades são pouco conhecidas, o que limita sua correta disposição ou aplicação. Com o intuito de diminuir a quantidade desse resíduo no meio ambiente, o presente estudo analisou a viabilidade da utilização das cinzas de caldeira (CC) coletadas durante o processo de limpeza. As CC foram caracterizadas física e quimicamente e para avaliação do seu efeito, produziram-se argamassas de proporção 1:3, em massa, com teores de substituição da cinza em relação ao agregado miúdo de 0\%, 5\%, 10\%, 15\% e 20\%, e relação água/cimento fixada em 0,7 . As propriedades avaliadas nas argamassas no estado fresco foram índice de consistência, densidade de massa e teor de ar incorporado, e no estado endurecido, absorção de água, índice de vazios, resistência à compressão axial e resistência à tração na flexão. Os resultados demonstraram que com 0 aumento do teor de substituição da areia pela CC houve uma redução na trabalhabilidade das argamassas, um aumento no teor de ar incorporado e consequente diminuição da densidade de massa. Houve ainda um aumento da absorção de água e da porosidade para todas as argamassas, manutenção das propriedades mecânicas nos teores de substituição de 10 e 15\% e aumento das resistências, no teor de $20 \%$, quando comparada com a argamassa sem adição, demonstrando assim a viabilidade do uso desta cinza como adição mineral.
\end{abstract}

Palavras-chave: Cinzas de caldeira, Eucalipto, Grãos, Adição mineral, Argamassas.

\section{Use of Biomass Ash Generated in the Malte Industry for the Production of Mortars}

\begin{abstract}
In malting plants, eucalyptus wood and agribusiness residues, such as grains and bark, are used as boiler fuel, generating ashes, whose properties are little known, which limits their correct disposition or application. In order to reduce the amount of this residue in the environment, the present study analyzed the feasibility of using the boiler ash (CC) collected during the cleaning process. The WCs were characterized physically and chemically and to evaluate their effect, air masses of proportion 1: 3, in mass, were produced, with contents of substitution of ash in relation to the fine aggregate of $0 \%, 5 \%, 10 \%, 15 \%$ and $20 \%$, and water / cement ratio set at 0.7 . The properties evaluated in mortars in the fresh state were consistency index, mass density and incorporated air content, and in the hardened state, water absorption, voids index, resistance to axial compression and tensile strength in flexion. The results showed that with the increase in the content of substitution of sand by $\mathrm{CC}$, there was a reduction in the workability of mortars, an increase in the content of incorporated air and a consequent decrease in the mass density. There was also an increase in water absorption and porosity for all mortars, maintenance of mechanical properties in the replacement contents of 10 and $15 \%$ and an increase in strengths, in the content of $20 \%$, when compared with mortar without addition, thus demonstrating the viability of using this ash as a mineral addition. Keywords: Boiler ashes, Eucalyptus, Grains, Mineral addition, Mortars.
\end{abstract}




\section{Uso de Cenizas de Biomasa Generadas en la Industria Maltera para la Producción de Morteros}

Resumen: En las malterías, la madera de eucalipto y los residuos de la agroindustria, co-mo granos y cortezas, se utilizan como combustible de caldera, generando ce-nizas, cuyas propiedades son poco conocidas, lo que limita su correcta dispo-sición o aplicación. Con el fin de reducir la cantidad de este residuo en el me-dio ambiente, el presente estudio analizó la viabilidad de utilizar las cenizas de caldera (CC) recolectadas durante el proceso de limpieza. Los WC se caracte-rizaron física y químicamente y para evaluar su efecto se produjeron masas de aire de proporción 1: 3, en masa, con contenidos de sustitución de cenizas con relación al agregado fino de $0 \%, 5 \%, 10 \%$, $15 \%$ y $20 \%$, y la relación agua / cemento se estableció en 0,7 . Las propiedades evaluadas en morteros en es-tado fresco fueron índice de consistencia, densidad de masa y contenido de aire incorporado, y en estado endurecido, absorción de agua, índice de vacíos, resistencia a la compresión axial y resistencia a la tracción en flexión. Los resultados mostraron que con el aumento en el contenido de sustitución de are-na por CC, se produjo una reducción en la trabajabilidad de los morteros, un aumento en el contenido de aire incorporado y una consecuente disminución en la densidad de masa. También hubo un aumento de la absorción de agua y la porosidad para todos los morteros, mantenimiento de las propiedades me-cánicas en los contenidos de reposición del 10 y $15 \%$ y un aumento de las re-sistencias, en el contenido del 20\%, cuando se compara con el mortero sin adición, demostrando así la viabilidad de utilizar esta ceniza como adición mineral.

Palabras clave: Ceniza de caldera, Eucalipto, Granos, Adición de minerales, Morteros.

\section{INTRODUÇ̃̃o}

A construção civil é um dos setores responsáveis pelos grandes impactos negativos causados à natureza, devido ao grande consumo de matérias-primas, energia e água, além da excessiva geração de resíduos. Dessa forma, os materiais de construção vêm sendo avaliados não apenas pelas suas propriedades e desempenho, mas também quanto à sustentabilidade, pela maneira como são produzidos e pelo impacto que o seu processamento gera ao meio ambiente (FREITAS, 2005). Dentre os diversos segmentos da construção civil, o que mais vem se preocupando com os conceitos de sustentabilidade é o de materiais, mais especificamente os que utilizam o cimento Portland como aglomerante principal (CANOVA; MIOTTO; DE MORI, 2015).

Para a produção de argamassas e concreto, utiliza-se também a areia, que é um agregado de origem natural e geologicamente é definida como o sedimento de grãos de quartzo. Ela pode ter sua origem em rios, em depósitos sedimentares, de cavas, de praias e dunas e a partir da britagem (BAUER, 2012). A extração de areia em rios tem degradado o ambiente aquático e em muitas vezes os impactos dessa extração são irreversíveis. Uma extração incorreta pode causar a perda da biodiversidade e a poluição das águas, devido ao combustível e óleos presentes nos equipamentos que são utilizados no processo e pela agitação de muitos sedimentos finos (FARIAS et al., 2012).

Devido aos riscos ambientais intrínsecos ao processo de extração de areia natural, inúmeras pesquisas têm sido realizadas sobre a viabilidade da substituição do agregado miúdo 
por resíduos das mais variadas origens. Dentre estes, tem-se as cinzas, geradas pela queima de outros resíduos, oriundos de indústrias como a de papel e celulose, olarias, termoelétricas e caldeiras de secagem de grãos da agricultura (MORAES, 2001; MANNAN; GANAPATHY, 2004; GONZÁLEZ-LÓPEZ et al., 2015). Enquanto resíduo, é um material sem destinação ou descartado e quando passa a ter aplicação específica, torna-se um subproduto (SILVEIRA, 1996).

Embora a produção de energia da biomassa seja de origem de reflorestamento ou também de resíduos agrícolas, sendo vista assim como um combustível renovável e sustentável, com baixas emissões de $\mathrm{CO}_{2}$, o aumento da produção de energias renováveis também é responsável por uma maior produção de cinzas, cuja maior parte é enviada para aterros (WERTHER, 2000; FARINHA; BRIT0; VEIGA, 2019). Isso deve ser evitado, pois acarreta diversos impactos, uma vez que as partículas finas de cinzas podem causar problemas respiratórios à saúde humana, além de contaminar os solos, lençóis freáticos e o ar, devido ao fato apresentar altos teores de cálcio, ferro, potássio e sílica, podendo conter metais pesados (MOR0; G0NÇALVES, 1995; MAEDA et al., 2008; CACUR0; WALDMAN, 2015).

De acordo com Fořt et al. (2020), a concentração de elementos perigosos nas cinzas volantes de biomassa é substancialmente menor em comparação com as cinzas volantes de carvão. Quanto às propriedades funcionais, as cinzas volantes de biomassa podem substituir até $30 \%$ do cimento Portland nos compósitos além disso, a cinza volante de biomassa sem qualquer pré-processamento pode servir como uma futura substituição da cinza volante de carvão em cimentos misturados.

A cinza de caldeiras (CC), por exemplo, é oriunda de indústrias que necessitam da caldeira com forma de produzir vapor e calor para atividades como secagem de grãos em cooperativas, secagem da cerâmica em olarias, termelétricas etc. A CC é derivada principalmente da queima do eucalipto e pinus, mas também possui parcela dos resíduos da própria indústria. Segundo Vasconcellos et al. (2004), na maioria das caldeiras três quartos da cinza produzida são muito leves e são arrastadas pelos gases, as chamadas cinzas volantes. As cinzas que possuem densidade maior e não são transportadas pelos gases são retiradas no fundo da caldeira, com grãos maiores são chamadas de cinzas residuais.

Devido ao grande porte das caldeiras na maioria das indústrias, a geração do resíduo ou subproduto que são as cinzas é também muito elevada, sendo um problema para a própria indústria. Com a necessidade de retirada a baixo custo, esse resíduo acaba sendo destinado incorretamente, depositado em áreas impróprias e sem o devido tratamento. A disposição de cinzas sem o correto tratamento gera a lixiviação o que possibilita que metais pesados e sulfatos penetrem no lençol freático contaminado a água (VASCONCELLOS et al., 2004). 
Teixeira et al. (2019) estudou o efeito da utilização de cinza volante de biomassa (CVB) na qualidade, durabilidade e sustentabilidade de argamassas e verificou que o uso de altas quantidades de CVB não levou a uma produção de argamassas com melhor desempenho, porém, quando a CVB foi utilizada em pequenas quantidades misturadas com cinzas volantes de carvão, obtiveram-se argamassas com resistência à compressão semelhantes à de uma argamassa de cimento, com menos carbonatação e com melhor desempenho ambiental.

Tosti et al. (2019) avaliou as propriedades mecânicas e ambientais de argamassas de cimento contendo cinzas volantes da combustão de biomassa como material cimentício secundário e concluiu que o desempenho técnico das argamassas de cimento foi influenciado pelo tipo e proporção de cinza volante misturada com cimento, porém, o desempenho ambiental foi impulsionado pela matriz de cimento que controlava a liberação de contaminantes, mantendo um bom desempenho técnico e ambiental.

Novais et. al. (2019) estudou o uso de resíduos provenientes da produção de celulose e papel, que atualmente são descartados em aterros sanitários a um custo enorme para a indústria e o meio ambiente, como preenchimento fino na produção de argamassas geopoliméricas à base de cinza volante de biomassa. As argamassas contendo resíduos apresentaram maior resistência à tração (até 71\%) e resistência à compressão (até 34\%), e menor absorção de água em comparação com a argamassa de referência, demonstrando a viabilidade do seu uso.

Dessa forma, por existir muitas indústrias que utilizam as caldeiras no processo de produção dos seus produtos na região de Guarapuava -PR, sendo a maltaria em questão a maior da América Latina, as cinzas oriundas da queima de madeira de eucalipto e de cascas de grãos nas caldeiras são matéria deste estudo, que tem como objetivo a caracterização destas cinzas de biomassa com vistas a seu uso como adição mineral na produção de argamassas.

\section{MATERIAL E MÉTODOS}

Na produção das argamassas foi utilizado o cimento Portland CP V- ARI, com teor de clínquer de $78 \%$, segundo o fabricante e com massa específica de $3,12 \mathrm{~g} / \mathrm{cm}^{3}$, determinada de acordo com a NBR 16605 (ABNT, 2017). A sua escolha se deu pelo fato de ser um cimento sem adições, a fim de qualificar melhor a reatividade das cinzas. 0 agregado miúdo utilizado foi a areia quartzosa de rio, cuja massa específica é de $2,62 \mathrm{~g} / \mathrm{cm}^{3}$, obtida segundo as prescrições da NBR NM 52 (ABNT, 2009) e módulo de finura de 1,53, determinado conforme a NBR NM 248 (ABNT, 
2003), classificando-a como areia fina. A curva granulométrica da areia está apresentada na Gráfico 1, com os limites superiores e inferiores estabelecidos pela NBR 7211 (ABNT, 2009).

Gráfico 1. Curva granulométrica do agregado miúdo

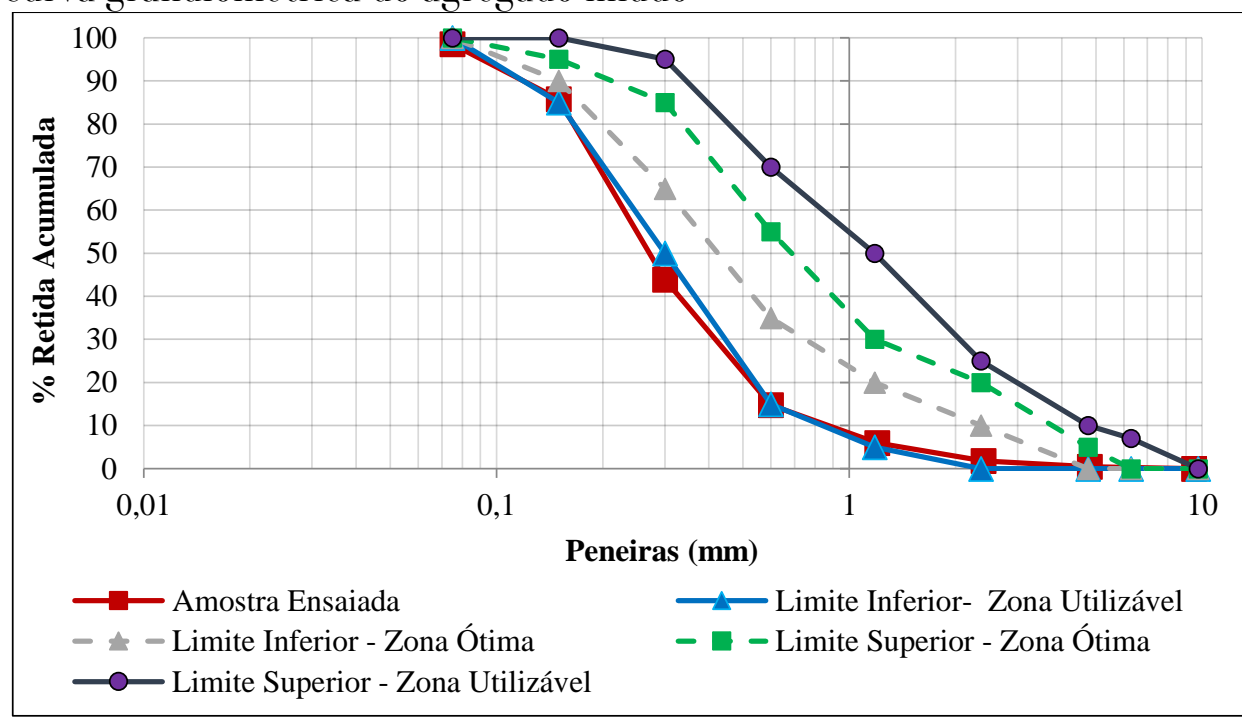

Fonte: Os autores.

A cinza de caldeira (CC) utilizada nesse trabalho foi fornecida pela Maltaria da Agraria e é oriunda da queima de eucalipto e resíduos da agroindústria, como grãos e cascas.

0 procedimento metodológico foi dividido em três fases experimentais: caracterização física da CC, caracterização química da CC e confecção e caracterização das argamassas, conforme descrito nos itens subsequentes.

\section{Caracterização Física da CC}

A cinza de caldeira (CC) foi submetida inicialmente a um processo de moagem, utilizando-se um moinho de martelo para moer os grãos maiores, que em seguida, passaram por um moedor de café, e por fim, por um processo manual, com o auxílio de um socador almofariz de porcelana. Ao final da triagem e moagem, totalizou-se $12 \mathrm{~kg}$ de CC (Figura 1). A moagem da cinza foi realizada com o objetivo de homogeneizar o material (redução de grãos aglomerados) e de reduzir a granulometria para aumentar a reatividade com o cimento. 


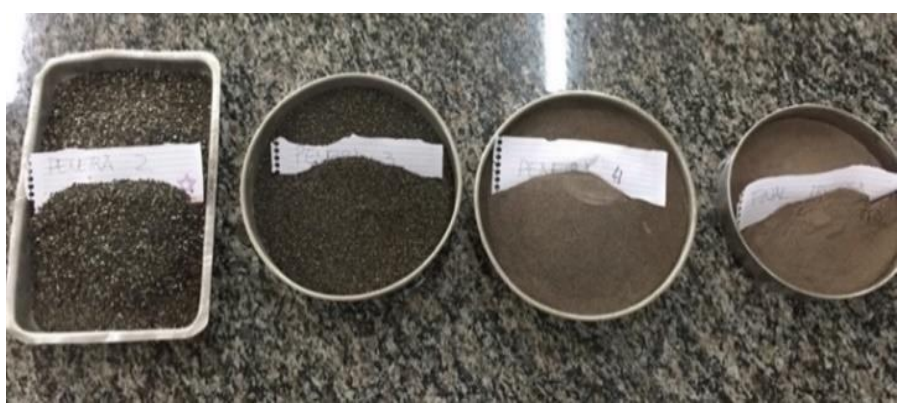

Figura 1. Cinza após moída e peneirada Fonte: 0s autores.

Posteriormente, as CC foram caracterizadas fisicamente, quanto à massa específica, conforme a NBR NM 52 (ABNT, 2009) e classificadas granulometricamente, de acordo com a NBR NM 248 (ABNT, 2003). Para a produção das argamassas, foram utilizados apenas os grãos de granulometria característica de agregado miúdo, ou seja, que passaram pela peneira 4,8 mm e ficaram retidos na peneira $0,075 \mathrm{~mm}$.

\section{Caracterização Química da CC}

Com relação à caracterização química, as CC foram submetidas ao ensaio para determinação do índice de atividade pozolânica, seguindo as prescrições da NBR 5751 (ABNT, 2015), conforme a exigências da NBR 12653 (ABNT, 2015). Além disso, também foram avaliadas quanto à sua composição química e teor de matéria orgânica residual.

A determinação da composição química, foi realizada a partir de uma microscopia eletrônica de varredura (MEV), onde uma amostra de cinza escolhida aleatoriamente foi previamente encapsulada e analisada em quatro pontos. Para determinação do teor de matéria orgânica residual, foi realizado o ensaio de perda ao fogo. Para isso, uma amostra de cinza, em um recipiente (cadinho) de alumina foi introduzida em uma mufla com temperatura inicial de $14^{\circ} \mathrm{C}$ até que fosse atingido $1000^{\circ} \mathrm{C}$, em atmosfera de ar, na presença de gás nitrogênio com um fluxo de $100 \mathrm{~mL} / \mathrm{min}$. A amostra se manteve sob $1000^{\circ} \mathrm{C}$ até que não fosse mais observada variação na massa do material. Assim, o teor de matéria orgânica pôde ser calculado pela diferença da massa inicial introduzida e após a queima a $1000^{\circ} \mathrm{C}$.

\section{Confecção e Caracterização das Argamassas}

Foram produzidas argamassas com substituição da areia pela CC, em quatro diferentes teores $(5,10,15$ e 20\%), além da referência, sem substituição. Para isso, foi utilizado o traço básico de 1:3, em massa, e mantida a relação água cimento fixada em 0,70. 0 consumo dos materiais para a produção das argamassas é apresentado na Tabela 1. 
Tabela 1. Consumo dos materiais para moldagem dos corpos de prova

\begin{tabular}{cccc}
\hline Teor de substitução & Cimento $\mathbf{( g )}$ & Areia $\mathbf{( g )}$ & CC $(\mathbf{g})$ \\
\hline $0 \%$ & 2401,59 & 7204,76 & 0,00 \\
$5 \%$ & 2401,59 & 6844,52 & 360,24 \\
$10 \%$ & 2401,59 & 6484,29 & 720,48 \\
$15 \%$ & 2401,59 & 6124,05 & 1080,71 \\
$20 \%$ & 2401,59 & 5763,81 & 1440,95 \\
\hline
\end{tabular}

Fonte: 0 s autores.

Os procedimentos de mistura para produção das argamassas seguiram o descrito na NBR 13276 (ABNT, 2016). Após produzidas, no estado fresco, as argamassas foram avaliadas quanto ao seu índice de consistência, de acordo com a NBR 13276 (ABNT, 2016), densidade de massa e teor de ar incorporado, segundo a NBR 13278 (ABNT, 2005).

Posteriormente, foram moldados onze corpos de prova cilíndricos $(5 \mathrm{x} 10 \mathrm{~cm})$ e seis corpos de prova prismáticos $(5 \times 5 \times 10 \mathrm{~cm})$, para cada teor de substituição. Após 24 horas de cura, os corpos de prova foram desformados, devidamente identificados e mergulhados em um tanque de água saturada de cal, onde permaneceram até as idades estabelecidas para a realização dos ensaios no estado endurecido, conforme apresentado na Tabela 2.

Tabela 2. Ensaios realizados no estado endurecido das argamassas

\begin{tabular}{ccccc}
\hline Ensaios & Idade & $\begin{array}{c}\text { Qtde. de } \\
\text { CP's/idade }\end{array}$ & $\begin{array}{c}\text { Dimensão dos } \\
\text { CP's }\end{array}$ & Norma \\
\hline Resistência à compressão axial & 7 e 28 dias & 4 & $5 x 10 \mathrm{~cm}$ & NBR 7215 (ABNT, 2009) \\
$\begin{array}{c}\text { Resistência à tração na flexão } \\
\text { Absorção de água e índice de } \\
\text { vazios }\end{array}$ & 28 dias 28 dias & 3 & $5 \times 5 \times 10 \mathrm{~cm}$ & NBR 13279 (ABNT, 2005) \\
\hline
\end{tabular}

Fonte: Os autores.

\section{RESULTADOS E DISCUSSÃ0}

\section{Caracterização Física da CC}

A CC foi caracterizada fisicamente e obteve-se 0 valor de massa específica de $2,31 \mathrm{~g} / \mathrm{cm}^{3}$, conforme a NBR 9776 (ABNT, 2009). Notou-se que a massa específica da CC é inferior à do agregado miúdo $\left(2,62 \mathrm{~g} / \mathrm{cm}^{3}\right)$, fator esse que pode ser explicado devido as partículas fibrosas presentes na cinza serem oriundas da queima incompleta do eucalipto e dos resíduos. Essa presença de partículas fibrosas pode reduzir a massa específica, aumentar o percentual de perda ao fogo e consequentemente a necessidade de água para manter a consistência desejada (BAHURUDEEN; SANTHANAM, 2015). 
Em termos comparativos com outras adições minerais como a cinza de casca de arroz (CCA), por exemplo, a massa específica encontrada é relativamente mais alta do que a encontrada por Rêgo (2015), que foi no intervalo de 2,10 e 2,25g/ $\mathrm{cm}^{3}$. Porém, mais baixa do que a massa específica da cinza de madeira de eucalipto (CME) encontrada por Couto (2018), que foi de $2,68 \mathrm{~g} / \mathrm{cm}^{3}$. Isso acontece porque a massa específica do material depende da composição química e da presença de possíveis contaminantes, o que leva diversos estudos terem resultados diferentes mesmo que os materiais sejam resíduos muito parecidos. Além disso o tratamento do resíduo efetuado diferentemente por cada autor também interfere.

Ainda fisicamente, foi determinada a composição da curva granulométrica da CC (Gráfico 2), que apresentou módulo de finura de 3,1l, segundo NBR NM 248 (ABNT, 2003) classificando-a como grossa.

Gráfico 2. Curva Granulométrica da CC

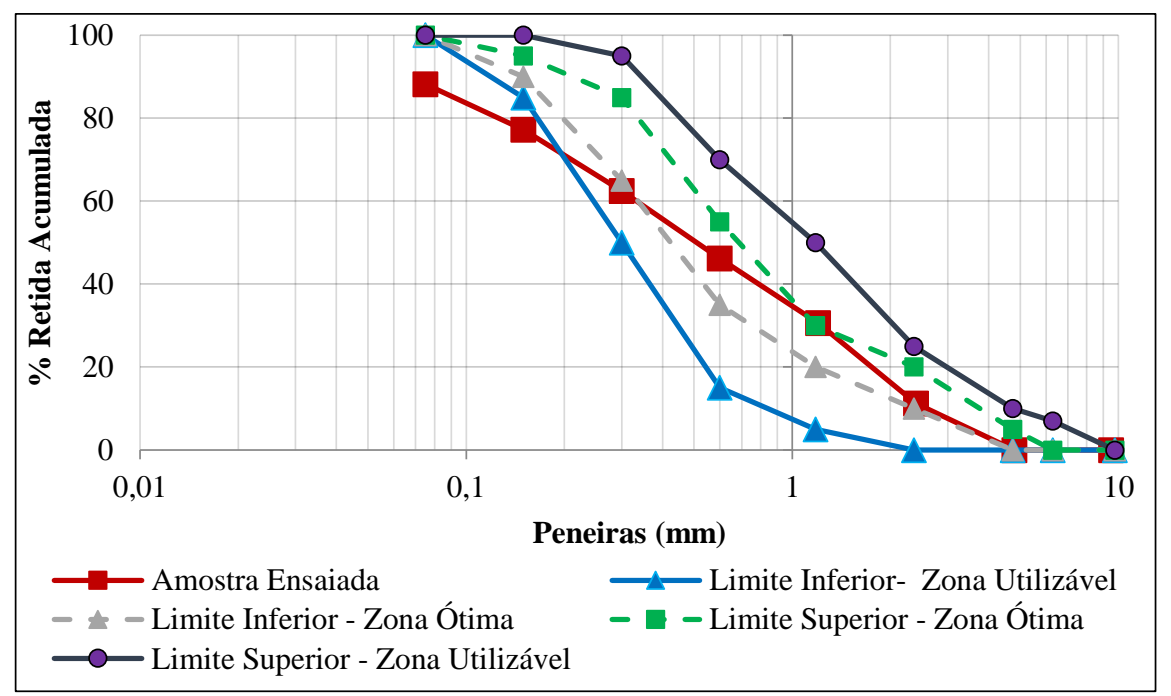

Fonte: 0s autores.

Quanto à distribuição granulométrica da CC foram observadas irregularidades em relação aos tamanhos, isso se deve ao fato de a CC não ser uniforme e possuir grãos maiores e outros menores devido a queima em temperaturas não controladas.

\section{Caracterização Química da CC}

Com relação à caracterização química, as CC foram submetidas ao ensaio para determinação do índice de atividade pozolânica e foram avaliadas quanto à sua composição química e teor de matéria orgânica residual 


\section{Índice de Atividade Pozolânica com Cal da CC}

Na caracterização química da CC, o ensaio de índice de atividade pozolânica (IAP) determinou que a CC analisada não pode ser classificada como material pozolânico por não cumprir a exigência prescrita pela NBR 12653 (ABNT, 2015), de possuir resistência à compressão de no mínimo 6 Mpa na reação com a cal. A média dos valores obtidos pela CC foi de 1,35Mpa, representando menos do $25 \%$ do mínimo exigido.

A reduzida atividade pozolânica da CC pode ser explicada pela combustão incompleta do eucalipto e dos grãos, resultando em uma grande quantia de carbono (SAMPAI0; SOUZA; GOUVEIA, 2004). Além disso, acredita-se que a Sílica (Si02) encontrada esteja na fase cristalina na estrutura morfológica da Sílica, provocada pela queima em temperatura não controladas, fato que, segundo Sampaio, Souza e Gouveia (2004), corrobora para a obtenção de resultados negativos quanto ao índice de atividade pozolânica encontrados, pois diminui a capacidade de reação da CC e consequentemente a torna menos positiva como adição mineral.

Porém esses índices estabelecidos pela norma têm sofrido algumas críticas por serem conservadores demais ou por não apresentarem concordância com o desempenho real das pozolanas. Segundo Tashima (2004), quando o mesmo realizou testes do IAP para CCA, não adquiriu resultados satisfatórios para obedecer a norma, mas ao testar a pozolana em argamassas e concretos obtinha ganho de resistência de 20 a 30\% em relação ao traço controle. Para ele, esse ganho de resistência se dá pela atividade pozolânica da CCA, sendo assim, incoerente os resultados obtidos no ensaio de IAP.

Nessa mesma linha, Silveira (1996) questionava esses resultados encontrados de baixa pozolanicidade, devido a presença de sílica cristalina. 0 autor acredita que o mais relevante é 0 resultado que a cinza possa oferecer, atribuindo em seus estudos que a reatividade do material não está, somente, relacionada com o seu amorfismo, mas também com a dosagem do material e com a presença de partículas finas que devem, por efeito físico, atuar conjuntamente com as reações pozolânicas.

\section{Microscopia eletrônica de varredura (MEV)}

Referente à composição química, no ensaio de microscopia eletrônica de varredura, a Figura 2 mostra as superfícies dos diferentes compostos ou elementos encontrados na CC, e a Tabela 3 demonstra quantidade em percentual de massa desses determinados elementos químicos presentes na amostra analisada. 

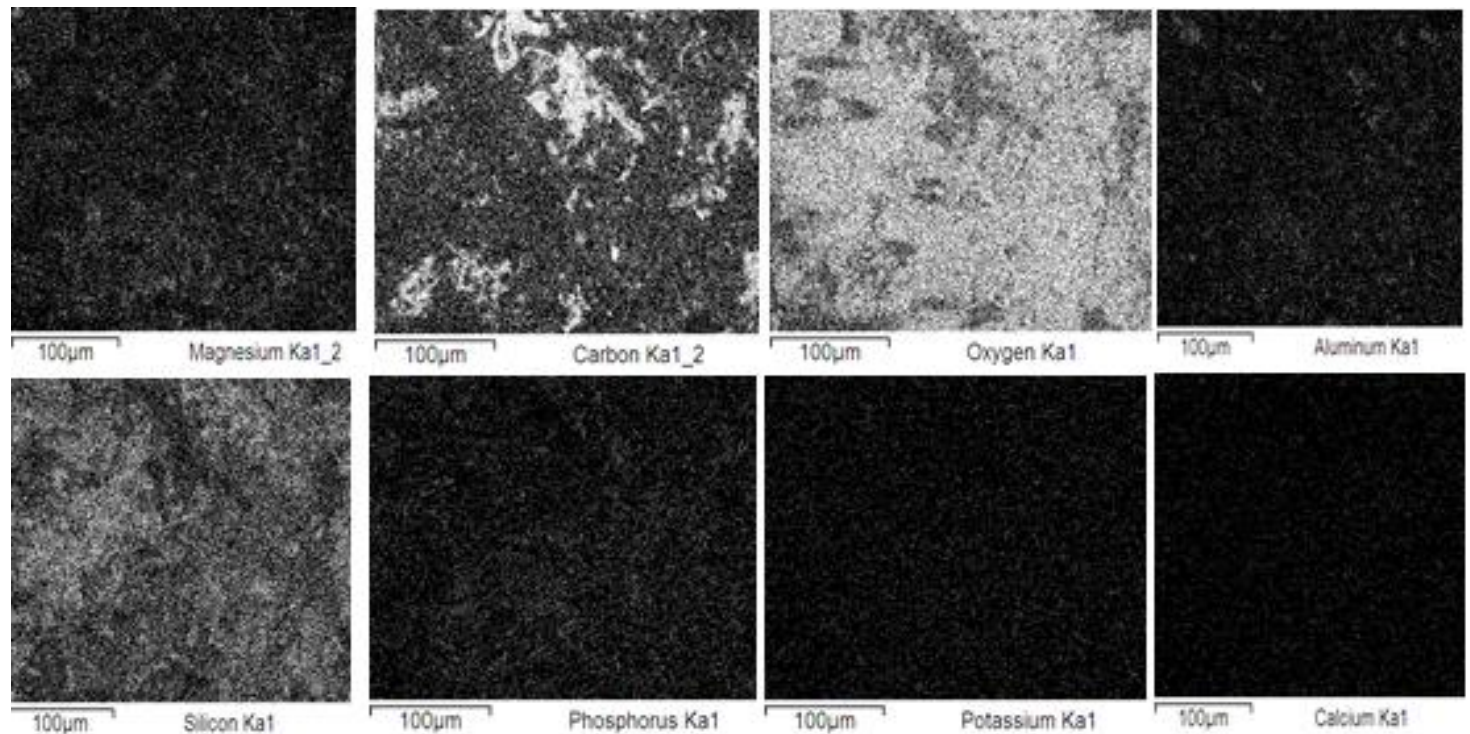

Figura 2. Amostras dos elementos encontrados no ensaio

Fonte: 0s autores.

Tabela 3. Quantidade em percentual de massa dos elementos químicos

\begin{tabular}{llllllllll}
\hline & $\mathrm{C}(\%)$ & $\mathbf{0 ( \% )}$ & $\mathrm{Mg}(\%)$ & $\mathrm{Al}(\%)$ & $\mathrm{Si}(\%)$ & $\mathrm{P}(\%)$ & $\mathrm{Cl}(\%)$ & $\mathrm{K}(\%)$ & $\mathrm{Ca}(\%)$ \\
\hline Espectro 1 & 17.088 & 41.250 & 2.142 & 1.135 & 13.947 & 3.737 & 1.369 & 10.944 & 8.389 \\
Espectro 2 & 45.163 & 25.873 & 1.082 & 0.547 & 9.697 & 1.986 & 1.255 & 8.321 & 6.075 \\
Espectro 3 & 8.720 & 36.633 & 4.766 & 1.170 & 8.984 & 4.100 & 4.215 & 12.423 & 18.990 \\
Espectro 4 & 10.659 & 49.969 & 2.881 & 0.510 & 15.059 & 2.450 & 0.000 & 7.574 & 10.897 \\
\hline
\end{tabular}

Fonte: Os autores.

Conforme os dados apresentados sobre a composição da CC, pode-se concluir que no geral a mesma apresenta uma composição homogênea, com exceção de alguns pontos, que possuem uma maior porcentagem de Carbono, como foi possível observar no Espectro 2.

Segundo De Paula (2006), a verificação de até 20\% de carbono não afeta as características mecânicas da argamassa, porém pode ser percebido um decréscimo dessa resistência quando o teor de Carbono passa de 30\% e isso pode acontecer devido à baixa quantidade de sílica quando se tem elevada quantidade de Carbono, fato que é comprovado na Tabela 3, Espectro 2 que possui altíssimo nível de Carbono e baixo de Sílica. Esse baixo nível de Sílica pode vir a ser explicado pelo material que é queimado, neste caso o eucalipt o, que durante a fase de crescimento absorve minerais do solo, que são imprescindíveis para o desenvolvimento da planta, porém são materiais inorgânicos, como por exemplo silicatos (BIRICIK et al., 1999). Assim, a presença de materiais inorgânicos, vai de encontro com os baixos teores de Sílica ativa (Si02) e pode vir a explicar o baixo índice de atividade pozolânica. 


\section{Termogravimetria}

Em relação à análise termogravimétrica da cinza, o Gráfico 3 apresenta a alteração de massa da amostra quando submetida a mufla até $1000^{\circ} \mathrm{C}$.

Gráfico 3. Ensaio em mufla, perda ao fogo

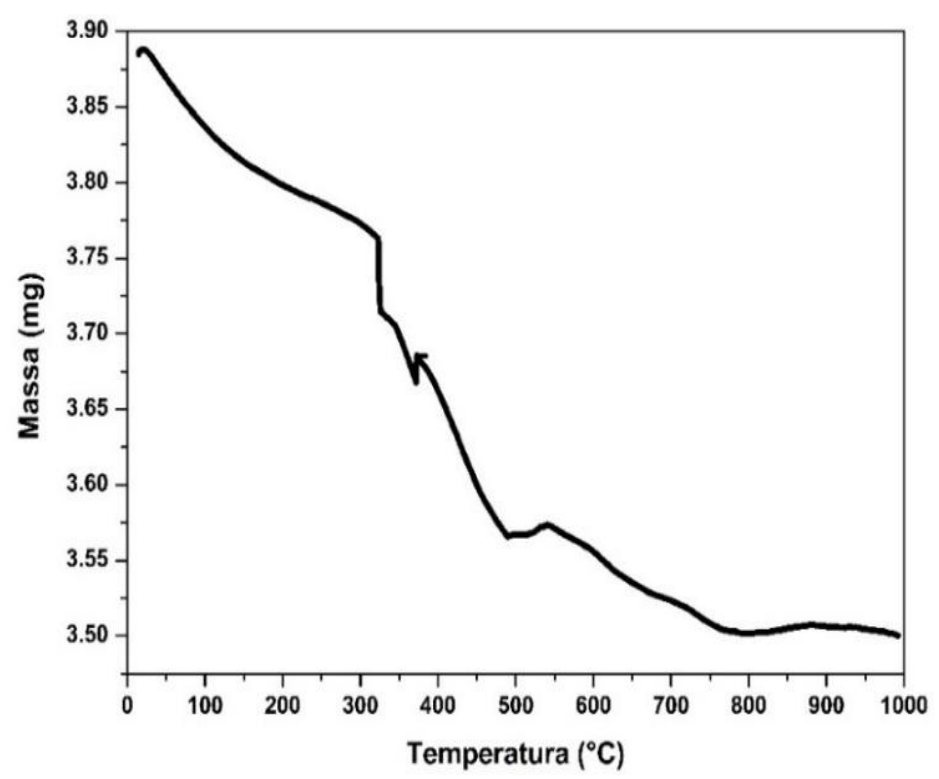

Fonte: 0s autores.

A massa inicial colocada no equipamento foi de 3,884mg e após o processo foi obtido uma massa de $3,500 \mathrm{mg}$, demonstrando uma perda de 9,9\%. Verifica-se que, como a cinza é resultante da queima há $300^{\circ} \mathrm{C}$, após a perda de água, a uma temperatura de $100^{\circ} \mathrm{C}$, não há nenhuma perda importante de massa até em torno $350^{\circ} \mathrm{C}$. A partir dessa temperatura verificase então uma redução da massa e uma estabilidade após os $800^{\circ} \mathrm{C}$.

\section{Propriedades avaliadas nas argamassas}

As argamassas foram avaliadas no estado fresco quanto ao seu índice de consistência, densidade de massa e teor de ar incorporado. No estado endurecido, foram realizados ensaios para determinação da absorção de água e índice de vazios, resistência à compressão axial e resistência à tração na flexão.

\section{Índice de consistência}

Os índices de consistências das argamassas, corresponde à média de três medidas de diâmetro, foram obtidos segundo a NBR 13276 (ABNT, 2016). 0 Gráfico 4 apresenta os resultados para os diferentes teores de substituição. 
Gráfico 4. Índice de Consistência da Argamassa

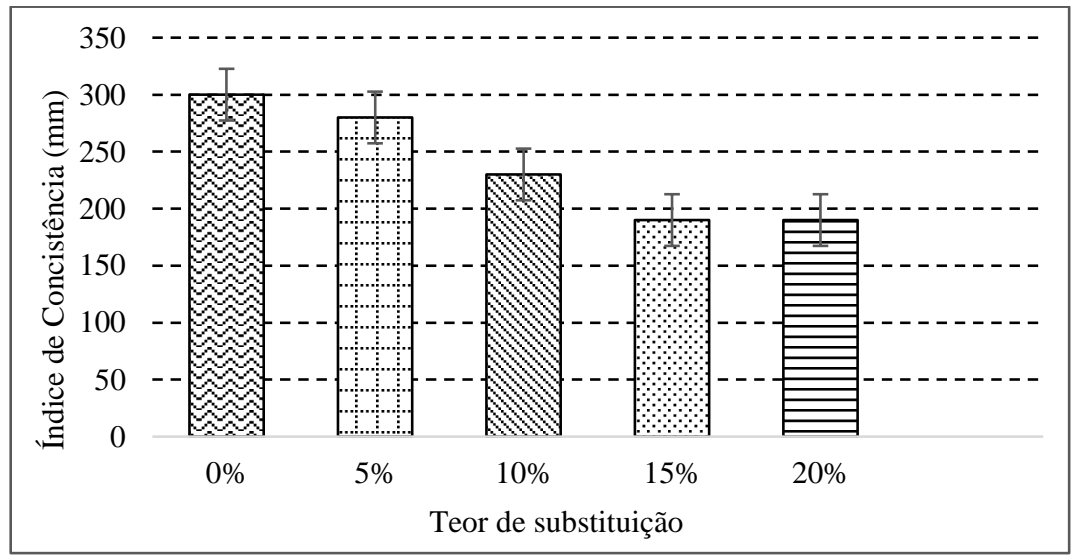

Fonte: 0 s autores.

A partir da análise do Gráfico 4, nota-se que o índice de consistência da argamassa diminuiu gradativamente conforme aumentou a porcentagem de substituição da areia pela CC. Isso deve-se, possivelmente, pela presença de CC na mistura deixá-la menos fluida, levando em consideração a mesma relação de água/cimento. Esse mesmo comportamento foi encontrado por Couto (2018), que avaliou a cinza de madeira de eucalipto como substituição do cimento.

A redução da fluidez da argamassa provocada pela CC pode ser explicada também pela morfologia da cinza, uma vez que as partículas possuem formatos irregulares, conforme observado por meio de microscópio, o que faz com que estas necessitem de mais água para o molhamento completo da sua superfície, o que não aconteceria caso a CC possuísse formato mais regular, como o da cinza volante, por exemplo, que possui partículas com formato arredondado e age praticamente como um plastificante na mistura, aumentado sua fluidez em até 220\% (MORAES, 2001).

Contudo, essa característica da CC pode vir a ser interessante em situações em que a cinza possa atuar como um meio retentor de água, segurando a água de hidratação do cimento. Couto (2018) exemplifica dias com a temperatura muito elevada ou concretos autoadensáveis, no qual se utiliza adições minerais para aumentar a capacidade de retenção de água do concreto.

\section{Densidade da argamassa e teor de ar incorporado}

A Tabela 4 apresenta os resultados obtidos tanto para densidade de massa como para 0 teor de ar incorporado nas argamassas, determinados segundo a NBR 13278 (ABNT, 2005), respectivamente. 
Tabela 4. Densidade de massa e teor de ar incorporado

\begin{tabular}{ccccccc}
\hline $\begin{array}{c}\text { Teor de } \\
\text { Substituição }\end{array}$ & $\begin{array}{c}\text { Densidade de } \\
\text { Massa }\left(\mathbf{g} / \mathbf{c m}^{\mathbf{3}}\right)\end{array}$ & $\begin{array}{c}\text { Desvio Padrão } \\
\left(\mathbf{g} / \mathbf{c m}^{\mathbf{3}}\right)\end{array}$ & CV & $\begin{array}{c}\text { Teor de Ar } \\
\text { Incorporado (\%) }\end{array}$ & $\begin{array}{c}\text { Desvio } \\
\text { Padrão (\%) }\end{array}$ & CV \\
\hline $0 \%$ & 1,844 & 0,018 & 0,99 & 8 & 0,83 & 10,37 \\
$5 \%$ & 1,818 & 0,026 & 1,45 & 9 & 1,25 & 13,88 \\
$10 \%$ & 1,808 & 0,005 & 0,28 & 10 & 1,24 & 12,42 \\
$15 \%$ & 1,798 & 0,004 & 0,22 & 10 & 0,22 & 2,18 \\
$20 \%$ & 1,762 & 0,044 & 2,50 & 12 & 2,18 & 18,18 \\
\hline
\end{tabular}

Fonte: 0 s autores.

Por meio da análise dos resultados, é possível observar uma pequena diminuição de densidade de massa das argamassas com o aumento dos teores de substituição, que chega a ter uma redução de até 8,22\%, em relação à argamassa de referência, para o teor de $20 \%$ de substituição de areia por CC. Isso está possivelmente aliado ao fato da massa específica da CC possuir valor inferior à da areia. Em contrapartida, estudos semelhantes obtiveram resultados divergentes, como relatado por De Paula (2006), aonde durante a análise de densidade de amostras com cinzas de cana de açúcar nas porcentagens de $0 \%, 10 \%, 20 \%, 30 \%$ não foi constatado alterações significativas. Outro estudo que demonstrou resultados insignificantes foi por Couto (2018), onde foi avaliado a substituição em 3\% de cinzas de madeira de eucalipto em relação ao cimento, tendo obtido valores de $2,003 \mathrm{~g} / \mathrm{cm}^{3}$ para o traço padrão e $2,002 \mathrm{~g} / \mathrm{cm}^{3}$ para o valor com adição de cinza. Quanto ao teor de ar incorporado, pode-se observar, na Tabela 4, um aumento gradual de mais de 4\% conforme se aumenta os teores de substituição da areia por CC, demonstrando assim que a CC não contribui para o empacotamento granulométrico, o que se pode explicar pelo módulo de finura das $\mathrm{CC}$ ser superior ao da areia, sendo de 3,11 e 1,53. Esse comportamento se mostra atípico com relação ao estudo de Canova, Miotto e De Mori (2015) onde durante a análise de argamassa com substituição da areia por cinzas de bagaço de cana de açúcar foi obtido uma redução no teor de ar incorporado conforme o teor de substituição foi aumentado.

\section{Absorção de água e índice de vazios}

Os resultados de absorção de água e índice de vazios, determinados de acordo com a NBR 9778 (ABNT, 2009), estão apresentados na Tabela 5.

Tabela 5. Absorção de água e índice de vazios

\begin{tabular}{ccccccc}
\hline $\begin{array}{c}\text { Teor de } \\
\text { Substituição }\end{array}$ & $\begin{array}{c}\text { Absorção de } \\
\text { água (\%) }\end{array}$ & $\begin{array}{c}\text { Desv. Padrão } \\
\text { (\%) }\end{array}$ & CV & $\begin{array}{c}\text { Índice de } \\
\text { Vazios (\%) }\end{array}$ & Desv. Padrão (\%) & CV \\
\hline $0 \%$ & 13,91 & 0,16 & 1,16 & 25,74 & 0,18 & 0,70 \\
$5 \%$ & 15,50 & 0,14 & 0,93 & 28,02 & 0,25 & 0,89 \\
$10 \%$ & 16,36 & 1,08 & 6,62 & 29,02 & 1,26 & 4,33 \\
$15 \%$ & 17,05 & 0,05 & 0,31 & 29,45 & 0,12 & 0,41 \\
$20 \%$ & 15,55 & 2,94 & 18,93 & 27,32 & 4,56 & 16,69 \\
\hline
\end{tabular}

Fonte: Os autores. 
Observa-se que tanto para a absorção de água quanto para o índice de vazios, os resultados são crescentes com o aumento das porcentagens de substituição, exceto para o teor de $20 \%$. 0 fato das argamassas com maiores teores de CC tenderem a ser mais porosas pode ser justificado pelas cinzas, em geral, possuírem textura rugosa e superfície porosa (SILVA et al., 2015).

\section{Resistência à compressão axial}

As argamassas foram avaliadas quanto à resistência à compressão axial aos 7 e 28 dias, de acordo com a NBR 7215 (ABNT, 2019). Os resultados, que consistem na resistência média de quatro corpos de prova, estão apresentados na Tabela 6 e ilustrados no Gráfico 5.

Tabela 6. Resistência média à compressão

\begin{tabular}{ccccc}
\hline Teor de Substituição & Idade (dias) & $\begin{array}{c}\text { Resistência média } \\
\text { (MPa) }\end{array}$ & Desv. Padrão (MPa) & CV \\
\hline \multirow{2}{*}{$0 \%$} & 7 & 12,303 & 1,442 & 11,73 \\
& 28 & 13,246 & 0,672 & 5,08 \\
\hline \multirow{2}{*}{$5 \%$} & 7 & 10,458 & 0,584 & 5,59 \\
& 28 & 11,758 & 0,350 & 2,98 \\
\hline \multirow{2}{*}{$10 \%$} & 7 & 10,228 & 0,858 & 8,39 \\
& 28 & 13,225 & 0,346 & 2,62 \\
\hline \multirow{2}{*}{$15 \%$} & 7 & 10,018 & 1,558 & 15,56 \\
& 28 & 13,225 & 0,346 & 2,62 \\
\hline \multirow{2}{*}{$20 \%$} & 7 & 10,081 & 0,734 & 7,28 \\
& 28 & 15,843 & 0,223 & 1,41 \\
\hline
\end{tabular}

Fonte: Os autores.

Gráfico 5. Resistência à compressão axial nas idades de 7 e 28 dias.

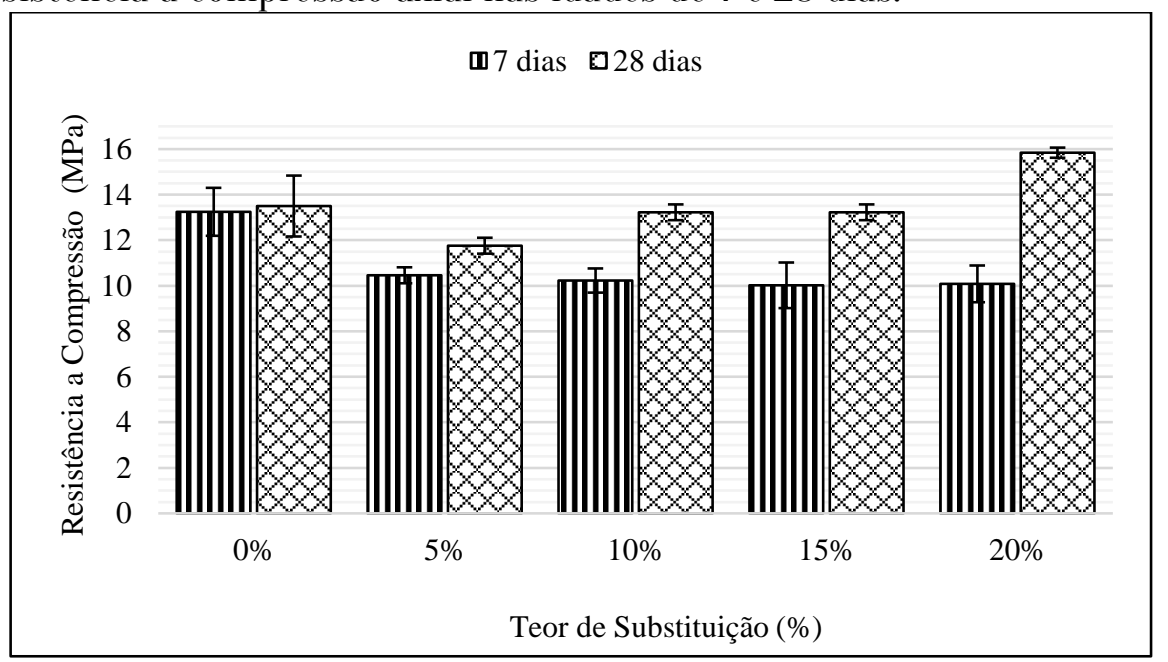

Fonte: 0s autores.

Pode-se observar por meio da análise dos resultados apresentados, que na idade de 7 dias, uma suave redução da resistência à compressão das argamassas, com o aumento dos teores 
de substituição da areia por CC, em comparação à referência. Aos 28 dias, no entanto, para os teores de substituição de 5, 10, 15 e 20\%, observou-se um aumento gradativo da resistência à compressão, superando o valor de resistência à compressão da referência, para o teor de substituição de $20 \%$.

0 aumento da resistência à compressão aos 28 dias pode ocorrer devido ao efeito fíler da CC, por meio do preenchimento dos vazios da pasta de argamassa, aumentando assim, a resistência e a compacidade do material. No entanto, essa hipótese não foi comprovada neste trabalho, uma vez que a CC apresentou alto índice de finura (3,11), superando em mais que duas vezes o da areia, o que a impossibilitaria de preencher os vazios.

Por outro lado, embora a CC não ter sido caracterizada como material pozolânico pela NBR 12653 (ABNT, 2015), acredita-se que este aumento de resistência possa estar relacionado à reação pozolânica da CC com o hidróxido de cálcio presente no cimento, uma vez que estes ganhos se deram aos 28 dias. Isto justifica-se, possivelmente pelo fato das reações pozolânicas terem início nas idades entre 7 e 15 dias, momento em que a hidratação do cimento já está em um estado mais avançado (ABNT, 2004). Esta análise corrobora com as pesquisas realizadas por Silveira (1996), que afirma que o resultado do estudo é mais importante do que a caracterização individual do material, uma vez que a reatividade do mesmo não está somente ligada ao seu amorfismo.

\section{Resistência à tração na flexão}

Na Tabela 7 e 0 Gráfico 6 são apresentados os resultados do ensaio de resistência à tração na flexão das argamassas, que foi realizado seguindo as prescrições da NBR 13279 (ABNT, 2005).

Tabela 7. Resistência média à tração na flexão

\begin{tabular}{ccccc}
\hline \multirow{2}{*}{ Teor de Substituição } & Idade (dias) & $\begin{array}{c}\text { Resistência Média } \\
(\mathbf{M P a})\end{array}$ & Desv. Padrão (MPa) & CV \\
\hline \multirow{2}{*}{$0 \%$} & 7 & 7,13 & 1,05 & 14,78 \\
& 28 & 7,33 & 0,83 & 12,02 \\
\hline \multirow{2}{*}{$5 \%$} & 7 & 6,36 & 0,53 & 8,35 \\
& 28 & 6,51 & 0,35 & 5,39 \\
\hline \multirow{2}{*}{$10 \%$} & 7 & 6,97 & 0,53 & 7,61 \\
& 28 & 8,66 & 1,00 & 15,32 \\
\hline \multirow{2}{*}{$15 \%$} & 7 & 6,44 & 0,74 & 9,64 \\
\hline \multirow{2}{*}{$20 \%$} & 28 & 7,66 & 0,81 & 10,23 \\
\end{tabular}

Fonte: Os autores. 
Gráfico 6. Resistência à tração nas idades de 7 e 28 dias

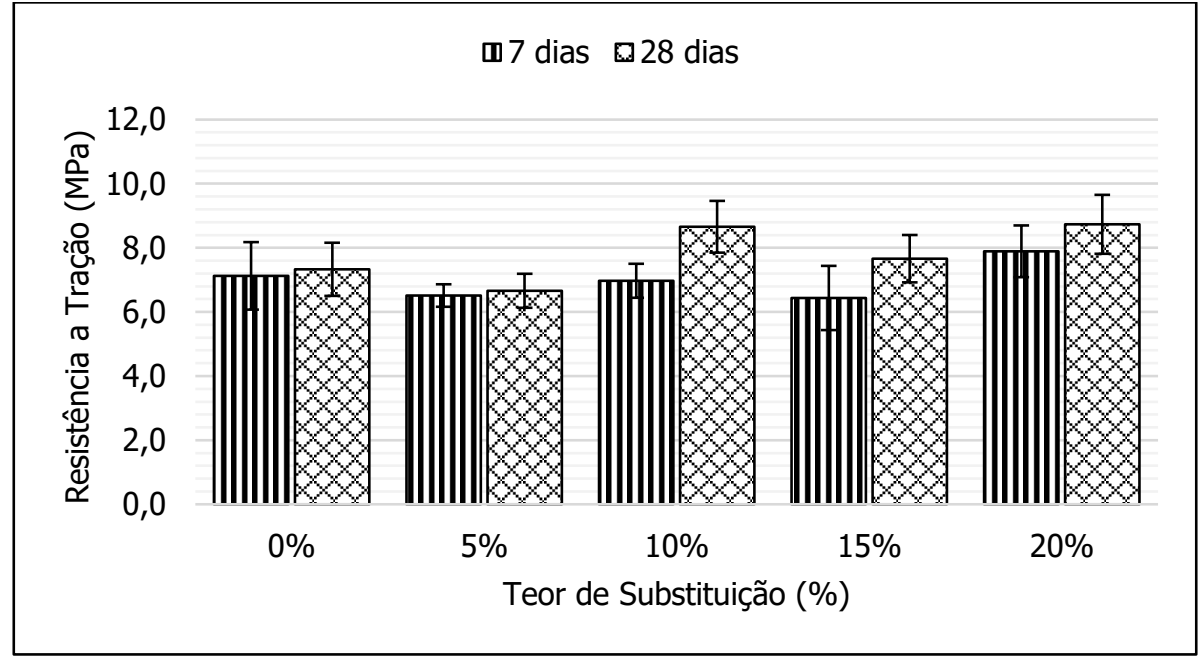

Fonte: 0s autores.

Com relação à resistência à tração das argamassas, por meio da análise dos resultados apresentados, verificou-se aos 7 dias, uma suave redução para os teores de substituição de 5, 10 e 15\% de CC. No teor de 20\%, no entanto, a resistência à tração mostrou-se superior à referência. Pôde-se observar, aos 28 dias, uma perda de resistência à tração, em relação a referência, apenas para a substituição com 5\% de CC. 0s demais teores de substituição apresentaram ligeiro aumento de resistência em relação à referência, sendo 0 aumento mais alto deles, para o teor de $20 \%$.

Canova, Miotto e De Mori (2015) em sua pesquisa com cinzas de bagaço de cana, verificou perante a substituição de areia por cinza bagaço de cana de açúcar, um aumento da resistência à tração com 5\% de substituição em relação à referência, seguindo por uma redução constante da resistência nas substituições subsequentes. Já o estudo de Borges (2017), com cinzas de eucalipto, a resistência à tração demonstrou um decréscimo constante, conforme foi aumentado o teor de cinzas na argamassa. Estas diferenças de comportamento podem estar relacionadas às diferentes origens dos resíduos utilizados nos estudos e à natureza mista da $\mathrm{CC}$, compostas pela queima de eucalipto e grãos.

\section{CONCLUSÃO}

Com este estudo verificou-se que embora a CC não tenha apresentado compostos químicos que permitam o desenvolvimento de atividades pozolânicas com os compostos hidratados do cimento, ainda assim foi possível a manutenção das propriedades mecânicas das argamassas, ao utilizá-las em substituição à areia. Recomenda-se em função das resistências à compressão e à tração, o teor de substituição de $20 \%$, para as argamassas, o que atesta que a 
sua utilização ser uma contribuição para o meio ambiente. Concluiu-se, portanto, que o uso da CC como substituição ao agregado miúdo natural para produção de argamassas é viável, podendo ser inserida como elemento inerte em materiais à base de cimento, indicando uma destinação adequada do resíduo com o potencial de reduzir a extração de materiais naturais utilizados para esse fim, desde que também seja investigada a durabilidade dos materiais para que se possam estabelecer melhores parâmetros de utilização.

\section{AGRADECIMENTOS}

À Maltaria Agraria que nos disponibilizou a matéria prima desse trabalho.

Ao técnico do laboratório de Engenharia Civil da Faculdade Guarapuava, que sempre esteve pronto para ajudar e incentivar a realização desse trabalho.

Ao Departamento de Química na Universidade Estadual do Centro-0este, em especial ao professor Mestre Fernando Ratuchne e professor Rafael Marangone, que cederam seu tempo e espaço para nos auxiliarem.

\section{REFERÊNCIAS BIBLIOGRÁFICAS}

AGRÁRIA MALTE. Disponível em: https://www.agraria.com.br/malte. Acesso em 23 de set. de 2020.

ASSOCIAÇÃO BRASILEIRA DE NORMAS TĖCNICAS. NBR 12653. Materiais pozolânicos - Requisitos. Rio de Janeiro, 2015.

NBR 13276. Argamassa para assentamento e revestimento de paredes e tetos - Determinação do índice de consistência. Rio de Janeiro, 2016.

NBR 13278. Argamassa para assentamento e revestimento de paredes e tetos - Determinação da densidade de massa e do teor de ar incorporado. Rio de Janeiro, 2005.

NBR 13279. Argamassa para assentamento e revestimento de paredes e tetos - Determinação da resistência à tração na flexão e à compressão. Rio de Janeiro, 2005.

2017.

NBR 16605. Cimento Portland e outros materiais em pó - Determinação da massa específica. Rio de Janeiro,

NBR 5751. Materiais pozolânicos - Determinação da atividade pozolânica com cal aos sete dias. Rio de Janeiro, 2015.

NBR 7211. Agregados para concreto - Especificação. Rio de Janeiro, 2019.

NBR 7215. Cimento Portland - Determinação da resistência à compressão de corpos de prova cilíndricos. Rio de Janeiro, 2019.

NBR 9778. Argamassa e concreto endurecidos - Determinação da absorção de água, índice de vazios e massa específica. Rio de Janeiro, 2009.

NBR NM 248. Agregados - Determinação da composição granulométrica. Rio de Janeiro, 2003. 
Janeiro, 2009.

NBR NM 52. Agregado miúdo - Determinação da massa específica e massa específica aparente. Rio de

BAHURUDEEN, A., SANTHANAM, M., Influence of different processing methods on the pozzolanic performance of sugarcane bagasse ash, Cement and Concrete Composites, v. 56, pp. 32-45, 2015.

BAUER, L. A. F. Materiais de Construção Civil: Novos Materiais para Construção Civil. 5. ed. Rio de Janeiro: Ltc. Pp 471, 2012.

BIRICIK, H.; AKÖZ, F.; BERKTAY, I.; TULGAR, A. N. Study of pozzolanic properties of wheat straw ash. Cement and Concrete Research, v. 29, n. 5, p. 637-643, 1999.

BORGES, D.; VALVERDE, D.; BIANCHI, G.; AKASAKI, J. L.; TRENTIN, T. F. S. Uso de cinza de madeira de eucalipto em compostos cimentícios, uma alternativa sustentável, Periódico Técnico e Científico Cidade Verdes, v. 5, n. 11, p. 89$103,2017$.

CACUR0, T. A.; WALDMAN, W. R. Cinzas da queima de biomassa: aplicações e potencialidades, Revista Virtual de Química, v. 07, n. 06, p. 2154-2165, 2015.

CANOVA, J. A.; MIOTTO, J. L.; DE MORI, L.M. A avaliação de argamassa mista de revestimento com substituição da areia natural por cinza de bagaço de cana-de-açúcar, Ciência \& Engenharia, v. 24, n. 1, pp 125-134, Jan. 2015.

COUTO, Á. F. Cinza de Madeira de Eucalipto como adição mineral em argamassas de cimento Portland. 2018. 121 f. Dissertação (Mestrado em Engenharia de Edificações e Saneamento) - Universidade Estadual de Londrina, 2018.

DE PAULA, M. 0. Potencial da cinza do bagaço da cana-de-açucar como material de substituição parcial de cimento Portland, Dissertação de Mestrado., UFV, Viçosa, MG, Brasil, 2006.

FARIAS, M. S. S.; LIMA, V. L. A.; DANTAS NETO, J.; LEITE, E. P. F.; ANDRADE, A. R. S. Degradação da bacia hidrográfica do rio cabelo e os efeitos ao meio ambiente, Principia, v. 10, n. 14, 2006.

FARINHA, C. B.; BRITO, J; VEIGA, R. Influence of forest biomass bottom ashes on the fresh, water and mechanical behaviour of cement-based mortars. Resources, Conservation and Recycling, v. 149, p. 750-759, 2019.

FOŘT, J.; ŠÁL, J.; ŠEVČ́́K, R.; DOLEŽELOVÁ, M.; KEPPERT, M.; JERMAN, M.; ZÁLESKÁ, M.; STEHEL, V.; ČERNÝA, R. Biomass fly ash as an alternative to coal fly ash in blended cements: Functional aspects. Construction and Building Materials, 2020.

FREITAS, E. S. Caracterização da cinza de bagaço de cana-de-açúcar do município de Campos dos Goyacazes para o uso na construção civil, Dissertação de M.Sc., UENF, Campos dos Goytacazes, RJ, Brasil, 2005.

GONZÁLEZ-LÓPEZ, J. R.; RAMOS-LARA, J. F.; ZALDIVAR-CADENA, A.; CHÁVEZ-GUERRER0, L.; MAGALLANES-RIVERA, R. X.; BURCIAGA-DÍAZ, 0. Small addition effect of agave biomass ashes in cement mortars, Fuel Processing Technology. V. 133, p. 35-42, 2015.

MAEDA, S.; DA SILVA, H. D.; CARDOSO, C. Resposta de Pinus taeda à aplicação de cinza de biomassa vegetal em Cambissolo Húmico, em vaso. Pesquisa Florestal Brasileira, Colombo, n.56, p.43-52, jan./jun. 2008.

MANNAN, M. A.; GANAPATHY, C. Concrete from an agricultural waste oil-palm shell (OPS). Building and Environment, v. 39, p. $441-448,2004$.

MORAES, R. C. Efeitos Físicos e Pozolânico das adições minerais sobre a resistência mecânica do concreto. 2001. 178 f. Dissertação (Mestrado) - Curso de Engenharia Civil, Universidade Federal de Santa Maria, Santa Maria, 2001.

MORO, L; GONÇALVES, J. L. M. Efeitos da "cinza" de biomassa florestal sobre a produtividade de povoamentos puros de eucalyptus grandis e avaliação financeira. Ipef, n. 48/49, p.18-27, 1995. Disponível em: https://www.ipef.br/publicacoes/scientia/nr48-49/cap03.pdf . Acesso em 16 set. 2020. 
NOVAIS, R. M.; CARVALHEIRAS, J.; SENFF, L.; LABRINCHA, J. A. Upcycling unexplored dregs and biomass fly ash from the paper and pulp industry in the production of eco-friendly geopolymer mortars: A preliminary assessment. Construction and Building Materials, v. 184, p. 464-472, 2018.

RÊGO, J. H. S.; NEPOMUCENO, A. A.; FIGUEIREDO, E. P.; HASPARYK, N. P. Microstructure of cement pastes with residual rice husk ash of low amorphous silica content, Construction and Building Materials, v. 80, pp. 56-68, 2015.

SAMPAI0, Z. L. M.; SOUZA, P. A. B. F.; GOUVEIA, B. G. Análise da influência das cinzas do bagaço de cana-de-açúcar no comportamento mecânico de concretos. Revista Ibracon de Estruturas e Materiais. v. 7, n. 4. p. 626 - 647, 2014.

SILVA, R. B.; FONTES, C. M. A.; LIMA, P. R. L.; GOMES, O. da F. M.; LIMA, L. G. L. M.; MOURA, R. C. de A.; TOLEDO FILHO, R. D. Cinzas de biomassa geradas na agroindústria do cacau: caracterização e uso em substituição ao cimento. Revista Ambiente Construído, Porto Alegre, v. 15, n. 4, p. 321-334, out./dez. 2015.

SILVEIRA, A. A. A utilização da cinza de casca de arroz com vistas a durabilidade de concretos: estudo do ataque por sulfatos. Porto Alegre, 1996. p.139. (Dissertação de Mestrado). Universidade Federal do Rio Grande do Sul.

TASHIMA, M. M. Influência da granulometria da cinza de casca de arroz em concretos, UNESP, Ilha Solteira, SP, 2004.

TOSTI, L.; ZOMEREN, A. van; PELS, J. R.; COMANS, R. N. J. Technical and environmental performance of lower carbon footprint cement mortars containing biomass fly ash as a secondary cementitious material. Resources, Conservation and Recycling, v. 134, p. 25-33, 2018.

TEIXEIRA, E. R.; MATEUS, R.; CAMÕES, A.; BRANCO, F. G. Quality and durability properties and life-cycle assessment of high volume biomass fly ash mortar. Construction and Building Materials, v. 197, p. 195-207, 2019

VASCONCELLOS, C. B. et al. 0 Aproveitamento da cinza de caldeira na construção Civil. Vértices, v. 6, p.131-148, 2004.

WERTHER, J.; SAENGER, M.; OGADA, T., SIAGI, Z. Combustion of Agricultural Residues, Progress in Energy and Combustion Science, v. 26, pp. 1-27, 2000. 